\title{
Multiple Myeloma: Molecular Pathogenesis and Disease Evolution
}

\author{
Michael Heider $^{a, b}$ Katharina Nickel ${ }^{a} \quad$ Marion Högner ${ }^{a} \quad$ Florian Bassermann $^{a, b}$ \\ aDepartment of Medicine III, Klinikum rechts der Isar, Technical University of Munich, Munich, Germany; \\ 'bTranslaTUM, Center for Translational Cancer Research, Technical University of Munich, Munich, Germany
}

\section{Keywords}

Multiple myeloma $\cdot$ Plasma cells $\cdot$ Pathogenesis $\cdot$ Genetics

\begin{abstract}
Background: Multiple myeloma is the second most common hematologic malignancy, which to date remains incurable despite advances in treatment strategies including the use of novel substances such as proteasome inhibitors, immunomodulatory drugs, and monoclonal antibodies. Summary: The bone marrow-based disease is preceded by the 2 sequential premalignant conditions: monoclonal gammopathy of undetermined significance and smoldering myeloma. Plasma cell leukemia and extramedullary disease occur, when malignant clones lose their dependency on the bone marrow. Key genetic features of these plasma cell dyscrasias include chromosomal aberrations such as translocations and hyperdiploidy, which occur during error-prone physiologic processes in B-cell development. Next-generation sequencing studies have identified mutations in major oncogenic pathways and tumor suppressors, which contribute to the pathogenesis of multiple myeloma and have revealed insights into the clonal evolution of the disease, particularly along different lines of therapy. More recently, the importance of epigenetic alterations and the role of the bone marrow microenvironment, including immune and osteogenic cells, have become evident. Key Messages: We herein review the current knowledge of the pathogenesis of multiple myeloma, which is crucial for the development of novel targeted therapeutic strategies. These can contribute to the endeavor to make multiple myeloma a curable disease.
\end{abstract}

(c) 2021 The Author(s).

Published by S. Karger AG, Basel

\section{Introduction}

Plasma cells are terminally differentiated B cells, which play an integral role in the humoral immune response by secreting antibodies. Errors in the physiologic events leading to plasma cell maturation and antigen specificity can propagate malignant transformation, leading to a variety of diseases termed plasma cell dyscrasias. The clinically most significant plasma cell disorder is multiple myeloma, which is the second most common hematologic malignancy and accounts for $10 \%$ thereof [1]. Clinical features of this bone marrow-based disease include bone destruction, hypercalcemia, renal failure, cytopenia, and immune paralysis [1]. Symptomatic multiple myeloma requires systemic treatment and can be preceded by 2 sequential premalignant conditions termed monoclonal gammopathy of undetermined significance (MGUS) and smoldering myeloma (SMM; also known as asymptomatic myeloma), all of which share several genetic features [2]. Precise understanding of the molecular pathogenesis and biology of each state of the disease is necessary to develop prognostic tools and novel therapeutic approaches. Technical advances in the detection of chromosomal aberrations via fluorescence in situ hybridization, mutational analysis using next-generation sequencing, epigenetic profiling, and investigations into the bone marrow microenvironment have added to the understanding of this family of hematologic malignancies. We herein review the current knowledge and provide novel insights into the molecular pathogenesis of plasma cell dyscrasias. 


\begin{tabular}{llll}
\hline IGH translocation & Genes affected & Frequency & Prognostic impact \\
\hline $\mathrm{t}(4 ; 14)$ & FGFR3, MMSET & $11-15 \%$ & High risk \\
$\mathrm{t}(6 ; 14)$ & CCND3 & Approximately 1-2\% & Standard risk \\
$\mathrm{t}(11 ; 14)$ & CCND1 & Approximately 15\% & Intermediate risk \\
$\mathrm{t}(14 ; 16)$ & MAF & $3-5 \%$ & High risk \\
$\mathrm{t}(14 ; 20)$ & MAFB & Approximately 1\% & High risk \\
\hline
\end{tabular}

Most common translocations with affected genes, frequencies, and prognostic impact. Data derived from $[12,20,39]$.

\section{Physiological B-Cell Development}

After undergoing immunoglobulin heavy and light chain rearrangement at the immature B-cell stage, B cells can transition from the bone marrow into the periphery and secondary lymphoid tissues for maturation. T-celldependent cytokine stimulation induces a complex B-cell activation in the germinal center that results in selection of B cells with higher-affinity B-cell receptors and longer lasting immunity. This process includes somatic alterations termed somatic hypermutation (SHM) and classswitch recombination (CSR), which are prone to genomic errors $[3,4]$. SHM of the heavy and light chains is important to increase the antigen-antibody affinity through mutation of the complementarity determining region [4]. CSR is a process that removes portions of the antibody heavy-chain locus, enabling the production of immunoglobulins of different isotypes with same antigenic specificity [5]. Both processes are mediated by the activationinduced cytidine deaminase, which introduces DNA double strand breaks [6-8].

\section{Translocations and Hyperdiploidy}

Translocations can be found in half of MGUS and MM patients [9]. As opposed to other B-cell malignancies, CSR errors are mainly thought to cause translocations in MM [10]. Most translocations involve the IgH locus (14q32), which puts oncogenes under the influence of the powerful IgH enhancer and thus result in upregulation (Table 1) [11, 12]. Translocations involving the immunoglobulin lambda (IgL) locus are present in $10 \%$ of patients with newly diagnosed MM and up to $20 \%$ in relapsedrefractory MM and are indicative of poor prognosis [13]. IgK translocations are even less frequent, occurring in $<5 \%$ of newly diagnosed MM [14]. Cyclin D (CCND) dysregulation is the most common result of IgH translocation [15]. It involves $\mathrm{t}(11 ; 14)(C C N D 1,15-20 \%), \mathrm{t}(12 ; 14)$ (CCND2, $1 \%)$, and $\mathrm{t}(6 ; 14)$ (CCND3, 1-4\%). IgH-NSD2 or $t(4 ; 14)$ is the second most common translocation and results in a dual dysregulation of NSD2 and FGFR3 $[16,17]$. NSD2 is thought to be the essential transforming element $[18,19]$. It contributes to increased proliferation, a change in cellular adhesion, and high tumorigenicity [20]. IgH-
MAF and IgH-MAFB translocations result from $\mathrm{t}(14 ; 16)$ and $t(14 ; 20)$, respectively $[21,22]$. Both genes belong to the MAF family, which are leucine zipper-containing transcription factors. MAF induces the expression of CCND2 resulting in accelerated cell division and DNA synthesis as well as integrin B7 leading to increased adhesion to bone marrow stromal cells [23]. Overexpression of MAFB induces proliferation and protects cells from drug-induced apoptosis $[4,24]$. Complimentary to translocations, $50-60 \%$ of all myelomas are hyperdiploid. Hyperdiploidy is hypothesized to occur during rapid germinal center proliferation that results in chromosome segregation errors [4]. Trisomies commonly affect odd chromosomes [25]. Nonhyperdiploid karyotypes can be further divided into hypodiploid (44/45 chromosomes; approximately $20 \%$ ), pseudodiploid (44/45 to $46 / 47$; approximately $35 \%$ ), near-tetraploid ( $>74$; approximately $10 \%$ ), and hyperhaploid karyotypes (24-34 chromosomes, rare) [26]. Nonhyperdiploid karyotypes are associated with a more aggressive clinical course, especially in the case of hypodiploidy and hyperhaploidy $[9,27-31]$.

\section{Monoclonal Gammopathy of Undetermined Significance}

MGUS is considered a premalignant clonal disorder and is classified based on the involved paraprotein (nonIgM, IgM, and light-chain MGUS) [32]. Diagnostic criteria are listed in Table 2 [33]. MGUS is present in approximately $3 \%$ of white individuals aged $>70$ years, and its incidence increases with age [34]. The most common subtype of heavy-chain MGUS is IgG (70\%), followed by $\operatorname{IgM}(15 \%), \operatorname{IgA}(12 \%)$, and biclonal gammopathy (3\%). In contrast to IgG, IgA, and biclonal gammopathy, which can precede MM, IgM MGUS is mostly a precursor for lymphoplasmocytic lymphoma [35]. Monoclonal gammopathy of renal significance is an important subgroup, which is characterized by renal impairment and/or proteinuria caused by paraprotein deposition [36] and progresses to end-stage renal disease in one-fifth of all cases [37]. Solitary plasmocytoma is a localized form of MM, confined to a single bone or extramedullary lesion, and is frequently associated with MGUS [38]. 
Table 2. Diagnostic criteria

\begin{tabular}{|c|c|c|c|c|}
\hline Diagnosis & MGUS & $\begin{array}{l}\text { Smoldering } \\
\text { myeloma }\end{array}$ & $\begin{array}{l}\text { Symptomatic } \\
\text { multiple myeloma }\end{array}$ & \\
\hline \multicolumn{5}{|l|}{ Criteria } \\
\hline \multirow[t]{2}{*}{ Clonal plasma cells in bone marrow } & $<10 \%$ & $10-60 \%$ & $\geq 10 \%$ & $\geq 60 \%$ \\
\hline & And & And/or & And/or & Or \\
\hline \multirow[t]{2}{*}{ M-protein (serum) } & $<30 \mathrm{~g} / \mathrm{L}$ & $\geq 30 \mathrm{~g} / \mathrm{L}$ & Detectable & \\
\hline & And & And/or & And/or & \\
\hline \multirow[t]{2}{*}{ Monoclonal light chain excretion (urine) } & $<500 \mathrm{mg} / 24 \mathrm{~h}$ & $\geq 500 \mathrm{mg} / 24 \mathrm{~h}$ & Detectable & \\
\hline & And & And & And & \\
\hline \multirow[t]{5}{*}{ End organ damage (CRAB-criteria) } & No & No & Yes & \\
\hline & And & & & \\
\hline & $\begin{array}{l}\text { Abnormal free light chain ratio } \\
\text { (only light chain type) }\end{array}$ & & & $\begin{array}{l}\text { Abnormal free light chain ratio } \\
\text { (only light chain type) }>100\end{array}$ \\
\hline & & & & \\
\hline & & & & $>1$ focal lesion on MRI \\
\hline
\end{tabular}

Diagnostic criteria for each disease stage assessed by bone marrow biopsy, serum and urine markers, and presence of organ damage. MGUS, monoclonal gammopathy of undetermined significance. Derived from [33].

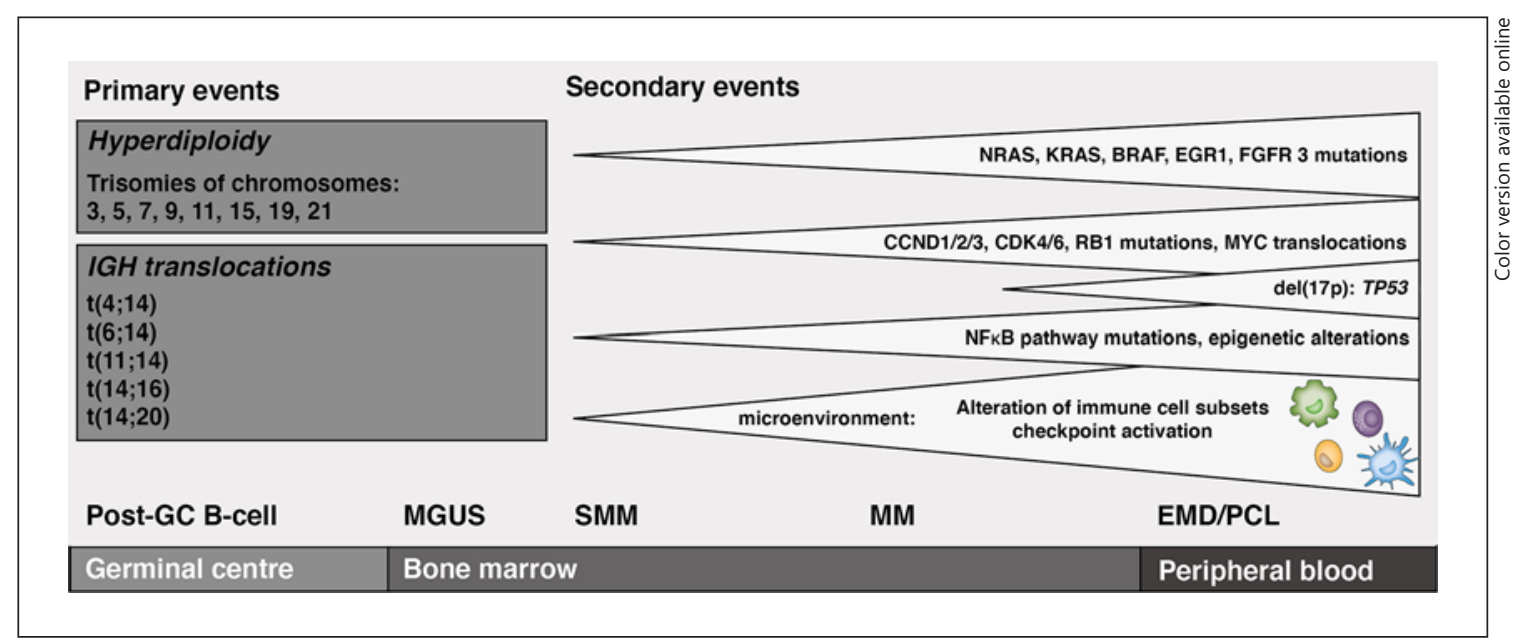

Fig. 1. Key features of multiple myeloma pathogenesis. Errors during physiologic B-cell development can result in primary genetic events such as hyperdiploidy and translocations. Further secondary events, such as mutations in oncogenic pathways, loss of tumor suppressor function through mutation or deletion, epigenetic alterations, and changes in the bone marrow microenvironment, cause the transition to symptomatic myeloma. End-stage disease is characterized by cells circulating in the blood stream/infiltrating other organs. MGUS, monoclonal gammopathy of undetermined significance; SMM, smoldering multiple myeloma; MM, multiple myeloma; EMD, extramedullary disease; PCL, plasma cell leukemia. Illustration adapted from [47].

\section{Mutational Landscape in SMM and MM}

The risk of progression to multiple myeloma is around $1 \%$ per year [35]. A variety of further genetic aberrations contribute to transformation of MGUS to MM. The crucial pathomechanism lies in the deregulation of oncogenic pathways rather than in single-gene mutations [39]. SMM is an intermediate condition with a higher disease burden than MGUS, which still lacks organ damage (Table 2) [34]. The progression risk of smoldering myeloma to active myeloma is about $10 \%$ per year in the first 5 years, $3 \%$ for the next 5 years, and $1 \% 10$ years after initial diagnosis $[2,40]$. This observation led to the conclusion that there are 2 main mechanisms of myeloma progression. In the "static progression model," the malignant population is already defined at SMM stage, and MM occurs by continuous proliferation of this clone. In the "spontaneous evolution model," disease progression occurs by clonal evolution with acquisition of further translocations, copy number aberrations, and mutations (shown in Fig. 1) [41, 42]. A recent study showed that whole-genome sequencing-based analyses could differentiate MM precursor conditions (MGUS and SMM) with a low or high risk of progression based on the absence or presence of key MM defining genetic events such 
Fig. 2. Branched clonal evolution patterns in plasma cell disorders. Clonal evolution of MM follows a branched pattern from an original propagating cell to symptomatic disease. Several clones may be present at each stage. Treatment can reset the clonal heterogeneity, and different clones can lead to relapse. MGUS, monoclonal gammopathy of undetermined significance; SMM, smoldering multiple myeloma; MM, multiple myeloma; EMD, extramedullary disease; PCL, plasma cell leukemia. Illustration adapted from [20].

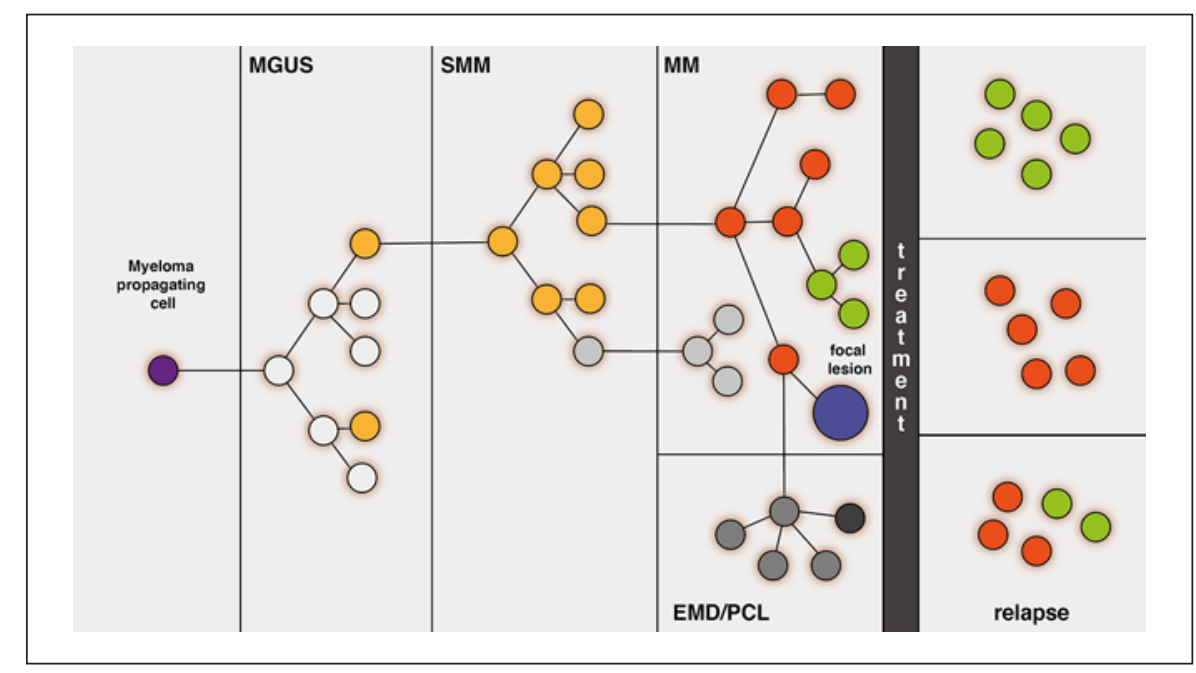

as chromothripsis, templated insertions, mutations in driver genes, and aneuploidy [43]. The frequency of mutations in $\mathrm{MM}$ has been determined by next-generation sequencing at about 60 mutations per patient [12] and is thus much higher than in patients with acute leukemias but lower than in solid tumor patients [44]. More than 60 recurrent mutations in driver genes have been identified [45]. Recent studies have shed light on the complex chronological order of MM-driving events using wholegenome sequencing approaches and have determined oncogenic point mutations to occur at rather later disease stages as opposed to disease-driving complex structural events [46]. In about $50 \%$ of myeloma patients, mutations induce aberrant signaling in the MAPK/ERK pathway (NRAS, KRAS, BRAF and EGR1, and FGFR3) [47]. About $15 \%$ of MM patients show mutations affecting DNA repair pathways like TP53, ATR, ATM, and ZFHX4 genes, which are associated with shorter survival $[48,49]$. Moreover, mutations involving the NFKB pathway can be detected in about $20 \%$ of MM patients, affecting TRAF3, NFKBIA, BIRC2/3, or CYLD genes [50]. Alteration of the PI3K pathway occurs in patients with MAF translocations [51]. Mutations in the CCND1/2/3,CDK4/6, and $R B 1$ genes deregulate cell cycle control mechanisms and are associated with unfavorable outcomes [48, 49]. To facilitate the export of cellular metabolites such as lactate and sustain the high need for nutrients, MM cells upregulate the expression of metabolically active transmembrane complexes. Their destabilization marks a major means by which IMiDs exert their antimyeloma efficacy $[52,53]$. Last, epigenetic changes leading to global DNA hypomethylation and gene-specific DNA hypermethylation play an important role in the progression of MGUS to myeloma [54]. This can be observed in a subgroup of patients with $\mathrm{t}(4 ; 14)$ and overexpression of MMSET which encodes a histone methyltransferase transcriptional repressor, leading to DNA hypermethylation [55].

\section{High-Risk, Extramedullary MM and Plasma Cell} Leukemia

Despite the recent improvements in therapy for MM patients, a group of high-risk disease patients consistently demonstrates poor outcomes upon standard therapy [56]. High-risk disease, which is present in $20-30 \%$ of all cases, cannot be defined by a single pathogenic mechanism, but rather arises from the interplay of several genetic lesions leading to high proliferation rates, evasion of apoptosis, and therapy resistance [20]. This is, in part, achieved by strong dysregulation of the G1/S checkpoint, further proliferation signaling via MYC, RAS-ERK, and NFKB pathways, aberrant signaling within the bone marrow niche, and loss or mutation of the tumor suppressor genes $R B 1$ and TP53 [20]. Next to IGH translocations such as $t(4 ; 14)$ and $t(14 ; 16)$, which have been associated with adverse outcomes, gain of chromosome 1q21 has recently evolved as another poor prognostic marker [57, 58]. Biallelic inactivation of TP53, either by homozygous deletion (del[17p]) or concurrent mutation, is considered a marker for ultra high-risk disease [49]. In advanced disease stages, some MM clones lose their dependency on the bone marrow microenvironment and can be found circulating in the bloodstream or infiltrating other organs. Plasma cell leukemia is historically defined by the presence of $>20 \%$ or $>2 \times 10^{9}$ clonal plasma cells in the peripheral bloodstream [59], whereas extramedullary disease is marked by proliferation and infiltration of $\mathrm{MM}$ cells in various extramedullary organs [60].

\section{Clonal Evolution of MM Disease}

Traditional cancer progression models proposed a linear process, in which a single malignant cell gives rise to clonal progeny, which acquires further genetic hits [61]. This applies in part to multiple myeloma; however, current studies have revealed a more branched evolutionary pattern according to Darwinian principles of natural se- 
lection (shown in Fig. 2) $[44,62]$. This is in line with patterns seen in acute myeloid leukemia and other hematologic malignancies $[63,64]$. Evolutionary patterns become evident especially in patients at relapse after therapy. A recent study demonstrated that patients at relapse after achieving a complete response had a predominantly branching evolutionary pattern with a greater mutational burden, an altered mutational profile, acquired structural aberrations, and biallelic inactivation of tumor suppressor genes, while patients at relapse after a partial response showed a largely stable mutational and structural profile [65]. Induction therapy reduces the tumor load and can be considered as an evolutionary restriction point, which resets intraclonal dynamics (shown in Fig. 2). Consolidation and maintenance therapy can then control more indolent clones, which persist after induction therapy, leading to a longer survival [66]. Mutations in known MMdriving genes (e.g., KRAS), segmental copy number alterations, and inactivation of tumor suppressors, such as TP53, drive disease progression by Darwinian clonal evolution, and both mutations in such genes, as well as branched evolution itself, have been associated with an adverse prognosis [67-69]. Another complexity arises from intrapatient spatial heterogeneity, which was shown to be present in $75 \%$ of patients analyzed by multiregion sequencing [70]. Biopsies taken from the usual sampling site, the iliac crest, might not provide a representative image of all, possibly high-risk clones, which might be present at other sites or focal lesions. This poses a significant challenge to targeted therapy in multiple myeloma.

\section{Microenvironment}

Since patients with MGUS or SMM show IgH translocations and/or hyperdiploidy, other factors seem to be necessary for MM progression. Late oncogenic events are thought to occur in the bone marrow, after the initial clone is completely differentiated into a long-lived plasma cell [39]. This implies an important role of the microenvironment for tumor progression $[34,71]$. The microenvironment includes cellular elements like bone marrow stroma cells, mesenchymal stem cells, endothelial cells, immune cells, and soluble factors. The bone marrow microenvironment in MM patients has been shown to differ in its composition compared to that of healthy individuals [72]. Pro-proliferative, antiapoptotic, and chemotactic cytokines such as IL6, CXCL12, IGF1, and VEGFA mediate $\mathrm{MM}$ cell growth, survival and migration, and following treatment, the development of drug resistance in the bone marrow microenvironment [73]. Moreover, myeloma cells also produce cytokines such as TNF- $\alpha$, TGF- $\beta$, and VEGF, resulting in a positive feedback loop [74].

Molecular Pathogenesis of MM

\section{Osteogenic Niche}

Osteoblasts are responsible for apposition of new bone and counterbalance the function of osteoclasts, the boneresorbing cells. Various hormones, nutrients, drugs, and disease states influence the function of osteoclasts and osteoblasts, normally providing an equilibrium and thus guaranteeing adequate bone mass [75]. In MM patients, the osteoblastic niche is depleted in favor of an overabundance of osteoclasts, which support cancer cell proliferation, resistance to apoptosis, and whose aberrant activity is responsible for lytic lesions and ultimately bone disease [76]. Molecular mechanisms of the antiosteoblastic effects of MM cells include downregulation of Run2 in MSCs and differentiated osteoblast progenitors, increased production of WNT pathway inhibitors including DickkopfWNT signaling pathway inhibitor 1 (DKK1), secretion of antiosteoblastic factors such as IL-3, TGF- $\beta$, hepatocyte growth factor, and constitutive activation of the Notch pathway [77-81]. Increased osteoclastogenesis in $\mathrm{MM}$ is largely determined by a loss of the balance between the pro-osteoclastogenic RANKL and the anti-osteoclastogenic RANK decoy receptor osteoprotegerin [82]. A maladaptive prosurvival and bidirectional loop also exists among osteoclasts and MM cells [83]. Osteoclasts contribute to MM pathogenesis, not only via their bone-resorbing properties which results in MM-related bone disease manifesting as osteopenia, lytic lesions, and eventually pathological fractures but also by secreting IL-6 and osteopontin, thus stimulating MM proliferation and angiogenesis, respectively [84]. In return, MM cells promote osteoclast differentiation and activity $[85,86]$.

\section{Immune Cells}

Several studies have demonstrated the capacity of innate and adaptive immune cells to mediate growth control of MGUS/MM [87]. MM cells can escape immunologic surveillance by inducing immune tolerance and Tcell anergy. A loss of effector function of T cells, NK cells, and NKT cells is associated with a progression to MM [88, 89]. The composition of lymphocytes present in the MM microenvironment substantially differs from that in healthy subjects $[90,91]$. TH17 cells are a distinct subset of CD4+ T helper cells characterized by a particular pattern of cytokine production and are abundant in the BM of MM patients [92-94]. TH17 cells suppress cancer immune surveillance by secreting $I L-10$ and IL-17, which also has a pro-osteoclastogenic effect [94-96]. Cytotoxic CD8+ T cells from MM patients differ from healthy counterparts in their repertoire of $\mathrm{T}$-cell receptor coreceptor molecules and show an increased expression of PD-1. PD-L1 is overexpressed on the surface of MM cells, which conveys further immune tolerance of MM [97, 98]. Although PD-L1 is expressed on MM cells, single-agent $\mathrm{PD}-1$ blockade is not effective in MM, and combination 
regimens with checkpoint inhibitors have also rendered disappointing results, especially given an excessive toxicity in combination with IMiDs [99-101].

\section{Conclusion}

It has become clear that the pathogenesis of plasma cell disorders is characterized by primary genetic lesions such as translocations and hyperdiploidy, which occur during physiological B-cell development. The transition from a premalignant clone to symptomatic disease is then facilitated by somatic mutations in various oncogenic pathways and tumor suppressors, epigenetic alterations, and a tumor-promoting bone marrow microenvironment. The understanding of these complex processes will support the development of new targeted therapeutic strategies, which should be considered essential if we want to reach the goal of curing MM patients.

\section{Conflict of Interest Statement}

F.B. received honoraria and research funding from BMS/Celgene.

\section{Funding Sources}

F.B. receives funding from the European Research Commission (project BCM-UPS, Grant No. 682473) and the German Research Foundation (SFB1335, BA 2851/6-1).

\section{Author Contributions}

M.He., M.Hö., and K.N. performed literature research and drafted the manuscript. F.B. coordinated the work and wrote the final manuscript. All authors discussed and corrected the final version of the manuscript.

\section{References}

1 Rajkumar SV. Multiple myeloma: 2020 update on diagnosis, risk-stratification and management. Am J Hematol. 2020 May; 95(5):548-67.

2 Kyle RA, Remstein ED, Therneau TM, Dispenzieri A, Kurtin PJ, Hodnefield JM, et al. Clinical course and prognosis of smoldering (asymptomatic) multiple myeloma. N Engl J Med. 2007 Jun 21;356(25):2582-90.

3 Stocker JW, Osmond DG, Nossal GJ. Differentiation of lymphocytes in the mouse bone marrow. III. The adoptive response of bone marrow cells to a thymus cell-independent antigen. Immunology. 1974 Nov;27(5):795806.

4 Barwick BG, Gupta VA, Vertino PM, Boise LH. Cell of origin and genetic alterations in the pathogenesis of multiple myeloma. Front Immunol. 2019;10:1121.

5 von Schwedler U, Jäck HM, Wabl M. Circular DNA is a product of the immunoglobulin class switch rearrangement. Nature. 1990 May 31;345(6274):452-6.

6 Muramatsu M, Kinoshita K, Fagarasan S, Yamada S, Shinkai Y, Honjo T. Class switch recombination and hypermutation require activation-induced cytidine deaminase (AID), a potential RNA editing enzyme. Cell. 2000 Sep 1;102(5):553-63.

7 Robbiani DF, Bothmer A, Callen E, ReinaSan-Martin B, Dorsett Y, Difilippantonio S, et al. AID is required for the chromosomal breaks in c-myc that lead to $\mathrm{c}-\mathrm{myc} / \mathrm{IgH}$ translocations. Cell. 2008 Dec 12;135(6):1028-38.

8 Koduru S, Wong E, Strowig T, Sundaram R, Zhang L, Strout MP, et al. Dendritic cell-mediated activation-induced cytidine deaminase (AID)-dependent induction of genomic instability in human myeloma. Blood. 2012 Mar 8;119(10):2302-9.

9 Fonseca R, Debes-Marun CS, Picken EB, Dewald GW, Bryant SC, Winkler JM, et al. The recurrent IgH translocations are highly associated with nonhyperdiploid variant multiple myeloma. Blood. 2003 Oct 1;102(7):2562-7.

10 Gonzalez D, van der Burg M, Garcia-Sanz R, Fenton JA, Langerak AW, Gonzalez M, et al. Immunoglobulin gene rearrangements and the pathogenesis of multiple myeloma. Blood. 2007 Nov 1;110(9):3112-21.

11 Bergsagel PL, Kuehl WM. Molecular pathogenesis and a consequent classification of multiple myeloma. J Clin Oncol. 2005 Sep 10; 23(26):6333-8.

12 Manier S, Salem KZ, Park J, Landau DA, Getz G, Ghobrial IM. Genomic complexity of multiple myeloma and its clinical implications. Nat Rev Clin Oncol. 2017 Feb;14(2):100-13.

13 Barwick BG, Neri P, Bahlis NJ, Nooka AK, Dhodapkar MV, Jaye DL, et al. Multiple myeloma immunoglobulin lambda translocations portend poor prognosis. Nat Commun. 2019 Apr 23;10(1):1911.

14 Kuehl WM, Bergsagel PL. Multiple myeloma: evolving genetic events and host interactions. Nat Rev Cancer. 2002 Mar;2(3):175-87.

15 Bergsagel PL, Kuehl WM, Zhan F, Sawyer J, Barlogie B, Shaughnessy J Jr. Cyclin D dysregulation: an early and unifying pathogenic event in multiple myeloma. Blood. 2005 Jul 1; 106(1):296-303.

16 Chesi M, Nardini E, Brents LA, Schröck E, Ried T, Kuehl WM, et al. Frequent translocation $\mathrm{t}(4 ; 14)(\mathrm{p} 16.3 ; \mathrm{q} 32.3)$ in multiple myelo$\mathrm{ma}$ is associated with increased expression and activating mutations of fibroblast growth factor receptor 3. Nat Genet. 1997 Jul;16(3): 260-4.

17 Chesi M, Nardini E, Lim RS, Smith KD, Kuehl WM, Bergsagel PL. The $\mathrm{t}(4 ; 14)$ translocation in myeloma dysregulates both FGFR3 and a novel gene, MMSET, resulting in IgH/ MMSET hybrid transcripts. Blood. 1998 Nov 1;92(9):3025-34
18 Keats JJ, Reiman T, Maxwell CA, Taylor BJ, Larratt LM, Mant MJ, et al. In multiple myeloma, $\mathrm{t}(4 ; 14)(\mathrm{p} 16 ; \mathrm{q} 32)$ is an adverse prognostic factor irrespective of FGFR3 expression. Blood. 2003 Feb 15;101(4):1520-9.

19 Keats JJ, Maxwell CA, Taylor BJ, Hendzel MJ, Chesi M, Bergsagel PL, et al. Overexpression of transcripts originating from the MMSET locus characterizes all $t(4 ; 14)(\mathrm{p} 16 ; \mathrm{q} 32)$-positive multiple myeloma patients. Blood. 2005 May 15;105(10):4060-9.

20 Pawlyn C, Morgan GJ. Evolutionary biology of high-risk multiple myeloma. Nat Rev Cancer. 2017 Aug 24;17(9):543-56.

21 Chesi M, Bergsagel PL, Shonukan OO, Martelli ML, Brents LA, Chen T, et al. Frequent dysregulation of the $\mathrm{c}$-maf proto-oncogene at $16 q 23$ by translocation to an Ig locus in multiple myeloma. Blood. 1998 Jun 15;91(12): 4457-63.

22 Hanamura I, Iida S, Akano Y, Hayami Y, Kato M, Miura K, et al. Ectopic expression of MAFB gene in human myeloma cells carrying $(14 ; 20)$ (q32;q11) chromosomal translocations. Jpn J Cancer Res. 2001 Jun;92(6):638-44.

23 Hurt EM, Wiestner A, Rosenwald A, Shaffer AL, Campo E, Grogan T, et al. Overexpression of c-maf is a frequent oncogenic event in multiple myeloma that promotes proliferation and pathological interactions with bone marrow stroma. Cancer Cell. 2004 Feb;5(2):191-9.

24 Misiewicz-Krzeminska I, Sarasquete ME, Vicente-Dueñas C, Krzeminski P, Wiktorska K, Corchete LA, et al. Post-transcriptional modifications contribute to the upregulation of cyclin D2 in multiple myeloma. Clin Cancer Res. 2016 Jan 1;22(1):207-17.

25 Chng WJ, Ketterling RP, Fonseca R. Analysis of genetic abnormalities provides insights into genetic evolution of hyperdiploid myeloma. Genes Chromosomes Cancer. 2006 Dec; 45(12):1111-20. 
26 Debes-Marun CS, Dewald GW, Bryant S, Picken E, Santana-Dávila R, González-Paz N, et al. Chromosome abnormalities clustering and its implications for pathogenesis and prognosis in myeloma. Leukemia. 2003 Feb; 17(2):427-36

27 Smadja NV, Bastard C, Brigaudeau C, Leroux D, Fruchart C; Groupe Francais de Cytogenetique Hématologique. Hypodiploidy is a major prognostic factor in multiple myeloma. Blood. 2001 Oct 1;98(7):2229-38.

28 Fassas AB, Spencer T, Sawyer J, Zangari M, Lee CK, Anaissie E, et al. Both hypodiploidy and deletion of chromosome 13 independently confer poor prognosis in multiple myeloma. Br J Haematol. 2002 Sep;118(4):1041-7.

29 Fonseca R, Bergsagel PL, Drach J, Shaughnessy J, Gutierrez N, Stewart AK, et al. International Myeloma Working Group molecular classification of multiple myeloma: spotlight review. Leukemia. 2009 Dec;23(12):2210-21.

30 Walker BA, Leone PE, Chiecchio L, Dickens NJ, Jenner MW, Boyd KD, et al. A compendium of myeloma-associated chromosomal copy number abnormalities and their prognostic value. Blood. 2010 Oct 14;116(15):e5665.

31 Sawyer JR, Tian E, Shaughnessy JD Jr, Epstein J, Swanson CM, Stangeby C, et al. Hyperhaploidy is a novel high-risk cytogenetic subgroup in multiple myeloma. Leukemia. 2017 Mar;31(3):637-44.

32 Landgren O, Kyle RA, Pfeiffer RM, Katzmann JA, Caporaso NE, Hayes RB, et al. Monoclonal gammopathy of undetermined significance (MGUS) consistently precedes multiple myeloma: a prospective study. Blood. 2009 May 28;113(22):5412-7.

33 Rajkumar SV, Dimopoulos MA, Palumbo A Blade J, Merlini G, Mateos MV, et al. International Myeloma Working Group updated criteria for the diagnosis of multiple myeloma. Lancet Oncol. 2014 Nov;15(12):e538-48.

34 Kyle RA, Durie BG, Rajkumar SV, Landgren O, Blade J, Merlini G, et al. Monoclonal gammopathy of undetermined significance (MGUS) and smoldering (asymptomatic) multiple myeloma: IMWG consensus perspectives risk factors for progression and guidelines for monitoring and management. Leukemia. 2010 Jun;24(6):1121-7.

35 Kyle RA, Therneau TM, Rajkumar SV, Offord JR, Larson DR, Plevak MF, et al. A long-term study of prognosis in monoclonal gammopathy of undetermined significance. $\mathrm{N}$ Engl J Med. 2002 Feb 21;346(8):564-9.

36 Leung N, Bridoux F, Hutchison CA, Nasr SH Cockwell P, Fermand JP, et al. Monoclonal gammopathy of renal significance: when MGUS is no longer undetermined or insignificant. Blood. 2012 Nov 22;120(22):4292-5.

37 Nasr SH, Satoskar A, Markowitz GS, Valeri AM, Appel GB, Stokes MB, et al. Proliferative glomerulonephritis with monoclonal IgG deposits. J Am Soc Nephrol. 2009 Sep;20(9): 2055-64.

38 Grammatico S, Scalzulli E, Petrucci MT. Solitary plasmacytoma. Mediterr J Hematol Infect Dis. 2017;9(1):e2017052.

39 Morgan GJ, Walker BA, Davies FE. The genetic architecture of multiple myeloma. Nat Rev Cancer. 2012 Apr 12;12(5):335-48.
40 Rajkumar SV, Landgren O, Mateos MV Smoldering multiple myeloma. Blood. 2015 May 14;125(20):3069-75.

41 Bolli N, Maura F, Minvielle S, Gloznik D, Szalat R, Fullam A, et al. Genomic patterns of progression in smoldering multiple myeloma. Nat Commun. 2018 Aug 22;9(1):3363

42 Maura F, Bolli N, Rustad EH, Hultcrantz M, Munshi N, Landgren O. Moving from cancer burden to cancer genomics for smoldering myeloma: a review. JAMA Oncol. 2020 Mar $1 ; 6(3): 425-32$

43 Oben B, Froyen G, Maclachlan KH, Leongamornlert D, Abascal F, Zheng-Lin B, et al. Whole-genome sequencing reveals progressive versus stable myeloma precursor conditions as two distinct entities. Nat Commun. 2021 Mar 25;12(1):1861.

44 Corre J, Cleynen A, Robiou du Pont S, Buisson L, Bolli N, Attal M, et al. Multiple myeloma clonal evolution in homogeneously treated patients. Leukemia. 2018 Dec;32(12): 2636-47.

45 Walker BA, Mavrommatis K, Wardell CP, Ashby TC, Bauer M, Davies FE, et al. Identification of novel mutational drivers reveals oncogene dependencies in multiple myeloma. Blood. 2018 Aug 9;132(6):587-97.

46 Maura F, Bolli N, Angelopoulos N, Dawson KJ, Leongamornlert D, Martincorena I, et al. Genomic landscape and chronological reconstruction of driver events in multiple myeloma. Nat Commun. 2019 Aug 23;10(1):3835

47 Cardona-Benavides IJ, de Ramón C, Gutiérrez NC. Genetic abnormalities in multiple myeloma: prognostic and therapeutic implications. Cells. 2021 Feb 5;10(2):336.

48 Walker BA, Boyle EM, Wardell CP, Murison A, Begum DB, Dahir NM, et al. Mutational spectrum, copy number changes, and outcome: results of a sequencing study of patients with newly diagnosed myeloma. J Clin Oncol. 2015 Nov 20;33(33):3911-20.

49 Walker BA, Mavrommatis K, Wardell CP, Ashby TC, Bauer M, Davies F, et al. A highrisk, double-hit, group of newly diagnosed myeloma identified by genomic analysis. Leukemia. 2019 Jan;33(1):159-70.

50 Keats JJ, Fonseca R, Chesi M, Schop R, Baker A, Chng WJ, et al. Promiscuous mutations activate the noncanonical NF-kappaB pathway in multiple myeloma. Cancer Cell. 2007 Aug; 12(2):131-44.

51 Chapman MA, Lawrence MS, Keats JJ, Cibulskis K, Sougnez C, Schinzel AC, et al. Initial genome sequencing and analysis of multiple myeloma. Nature. 2011 Mar 24;471(7339): 467-72.

52 Eichner R, Heider M, Fernández-Sáiz V, van Bebber F, Garz AK, Lemeer S, et al. Immunomodulatory drugs disrupt the cereblonCD147-MCT1 axis to exert antitumor activity and teratogenicity. Nat Med. 2016 Jul;22(7): 735-43.

53 Heider M, Eichner R, Stroh J, Morath V, Kuisl A, Zecha J, et al. The IMiD target CRBN determines HSP90 activity toward transmembrane proteins essential in multiple myeloma. Mol Cell. 2021 Mar 18;81(6):1170-86.e10.
54 Walker BA, Wardell CP, Chiecchio L, Smith EM, Boyd KD, Neri A, et al. Aberrant global methylation patterns affect the molecular pathogenesis and prognosis of multiple myeloma. Blood. 2011 Jan 13;117(2):553-62

55 Marango J, Shimoyama M, Nishio H, Meyer JA, Min DJ, Sirulnik A, et al. The MMSET protein is a histone methyltransferase with characteristics of a transcriptional corepressor. Blood. 2008 Mar 15;111(6):3145-54.

56 Costa LJ, Usmani SZ. Defining and managing high-risk multiple myeloma: current concepts. J Natl Compr Canc Netw. 2020 Dec; 18(12):1730-7.

57 Sonneveld P, Avet-Loiseau H, Lonial S, Usmani S, Siegel D, Anderson KC, et al. Treatment of multiple myeloma with high-risk cytogenetics: a consensus of the International Myeloma Working Group. Blood. 2016 Jun 16;127(24):2955-62.

58 Schmidt TM, Fonseca R, Usmani SZ. Chromosome 1q21 abnormalities in multiple myeloma. Blood Cancer J. 2021 Apr 29;11(4):83.

59 Gundesen MT, Lund T, Moeller HEH, Abildgaard N. Plasma cell leukemia: definition, presentation, and treatment. Curr Oncol Rep. 2019 Jan 28;21(1):8.

60 Bhutani M, Foureau DM, Atrash S, Voorhees PM, Usmani SZ. Extramedullary multiple myeloma. Leukemia. 2020 Jan;34(1):1-20.

61 Nowell PC. The clonal evolution of tumor cell populations. Science. 1976 Oct 1;194(4260): 23-8.

62 Greaves M, Maley CC. Clonal evolution in cancer. Nature. 2012 Jan 18;481(7381):30613.

63 Ding L, Ley TJ, Larson DE, Miller CA, Koboldt DC, Welch JS, et al. Clonal evolution in relapsed acute myeloid leukaemia revealed by whole-genome sequencing. Nature. 2012 Jan 11;481(7382):506-10.

64 Landau DA, Carter SL, Getz G, Wu CJ. Clonal evolution in hematological malignancies and therapeutic implications. Leukemia. 2014 Jan;28(1):34-43.

65 Jones JR, Weinhold N, Ashby C, Walker BA, Wardell C, Pawlyn C, et al. Clonal evolution in myeloma: the impact of maintenance lenalidomide and depth of response on the genetics and sub-clonal structure of relapsed disease in uniformly treated newly diagnosed patients. Haematologica. 2019 Jul;104(7): 1440-50.

66 McCarthy PL, Holstein SA, Petrucci MT, Richardson PG, Hulin C, Tosi P, et al. Lenalidomide maintenance after autologous stem-cell transplantation in newly diagnosed multiple myeloma: a meta-analysis. J Clin Oncol. 2017 Oct 10;35(29):3279-89.

67 Weinhold N, Ashby C, Rasche L, Chavan SS, Stein C, Stephens OW, et al. Clonal selection and double-hit events involving tumor suppressor genes underlie relapse in myeloma. Blood. 2016 Sep 29;128(13):1735-44.

68 Boyle EM, Deshpande S, Tytarenko R, Ashby C, Wang Y, Bauer MA, et al. The molecular make up of smoldering myeloma highlights the evolutionary pathways leading to multiple myeloma. Nat Commun. 2021 Jan 12;12(1): 293. 
69 Croft J, Ellis S, Sherborne AL, Sharp K, Price A, Jenner MW, et al. Copy number evolution and its relationship with patient outcome-an analysis of 178 matched presentation-relapse tumor pairs from the myeloma XI trial. Leukemia. 2021 Jul;35(7):2043-53.

70 Rasche L, Chavan SS, Stephens OW, Patel PH, Tytarenko R, Ashby C, et al. Spatial genomic heterogeneity in multiple myeloma revealed by multi-region sequencing. Nat Commun. 2017 Aug 16;8(1):268.

71 Quail DF, Joyce JA. Microenvironmental regulation of tumor progression and metastasis. Nat Med. 2013 Nov;19(11):1423-37.

72 Bianchi G, Anderson KC. Understanding biology to tackle the disease: multiple myeloma from bench to bedside, and back. CA Cancer J Clin. 2014 Nov-Dec;64(6):422-44.

73 Hideshima T, Anderson KC. Molecular mechanisms of novel therapeutic approaches for multiple myeloma. Nat Rev Cancer. 2002 Dec;2(12):927-37.

74 Hideshima T, Mitsiades C, Tonon G, Richardson PG, Anderson KC. Understanding multiple myeloma pathogenesis in the bone marrow to identify new therapeutic targets. Nat Rev Cancer. 2007 Aug;7(8):585-98.

75 Harada S, Rodan GA. Control of osteoblast function and regulation of bone mass. Nature. 2003 May 15;423(6937):349-55.

76 Giuliani N, Rizzoli V. Myeloma cells and bone marrow osteoblast interactions: role in the development of osteolytic lesions in multiple myeloma. Leuk Lymphoma. 2007 Dec;48(12) 2323-9.

77 Tian E, Zhan F, Walker R, Rasmussen E, Ma $\mathrm{Y}$, Barlogie B, et al. The role of the Wnt-signaling antagonist DKK1 in the development of osteolytic lesions in multiple myeloma. N Engl J Med. 2003 Dec 25;349(26):2483-94.

78 Ehrlich LA, Chung HY, Ghobrial I, Choi SJ, Morandi F, Colla S, et al. IL-3 is a potential inhibitor of osteoblast differentiation in multiple myeloma. Blood. 2005 Aug 15;106(4): 1407-14.

79 Pinzone JJ, Hall BM, Thudi NK, Vonau M, Qiang YW, Rosol TJ, et al. The role of dickkopf-1 in bone development, homeostasis, and disease. Blood. 2009 Jan 15;113(3):51725.

$80 \mathrm{Xu}$ S, Evans H, Buckle C, De Veirman K, Hu $\mathrm{J}, \mathrm{Xu} \mathrm{D}$, et al. Impaired osteogenic differentiation of mesenchymal stem cells derived from multiple myeloma patients is associated with a blockade in the deactivation of the Notch signaling pathway. Leukemia. 2012 Dec; 26(12):2546-9.
81 Toscani D, Bolzoni M, Accardi F, Aversa F, Giuliani N. The osteoblastic niche in the context of multiple myeloma. Ann N Y Acad Sci. 2015 Jan;1335:45-62.

82 Raje N, Roodman GD. Advances in the biology and treatment of bone disease in multiple myeloma. Clin Cancer Res. 2011 Mar 15; 17(6):1278-86.

83 Abe M, Hiura K, Wilde J, Shioyasono A, Moriyama K, Hashimoto T, et al. Osteoclasts enhance myeloma cell growth and survival via cell-cell contact: a vicious cycle between bone destruction and myeloma expansion. Blood. 2004 Oct 15;104(8):2484-91.

84 Roodman GD. Pathogenesis of myeloma bone disease. J Cell Biochem. 2010 Feb 1; 109(2):283-91.

85 Yaccoby S, Wezeman MJ, Henderson A, Cottler-Fox M, Yi Q, Barlogie B, et al. Cancer and the microenvironment: myeloma-osteoclast interactions as a model. Cancer Res. 2004 Mar 15;64(6):2016-23.

86 Silbermann R, Roodman GD. Myeloma bone disease: pathophysiology and management. J Bone Oncol. 2013 Jun;2(2):59-69.

87 Dhodapkar MV. Harnessing host immune responses to preneoplasia: promise and challenges. Cancer Immunol Immunother. 2005 May;54(5):409-13.

88 Dhodapkar MV, Krasovsky J, Olson K. T cells from the tumor microenvironment of patients with progressive myeloma can generate strong, tumor-specific cytolytic responses to autologous, tumor-loaded dendritic cells. Proc Natl Acad Sci U S A. 2002 Oct 1;99(20): 13009-13.

89 Dhodapkar MV, Geller MD, Chang DH, Shimizu K, Fujii S, Dhodapkar KM, et al. A reversible defect in natural killer $\mathrm{T}$ cell function characterizes the progression of premalignant to malignant multiple myeloma. J Exp Med. 2003 Jun 16;197(12):1667-76

90 Braga WM, Atanackovic D, Colleoni GW. The role of regulatory T cells and TH17 cells in multiple myeloma. Clin Dev Immunol. 2012;2012:293479.

91 Favaloro J, Brown R, Aklilu E, Yang S, Suen $\mathrm{H}$, Hart D, et al. Myeloma skews regulatory T and pro-inflammatory $\mathrm{T}$ helper 17 cell balance in favor of a suppressive state. Leuk Lymphoma. 2014 May;55(5):1090-8.
92 Bettelli E, Carrier Y, Gao W, Korn T, Strom TB, Oukka M, et al. Reciprocal developmental pathways for the generation of pathogenic effector TH17 and regulatory T cells. Nature. 2006 May 11;441(7090):235-8.

93 Dong C. TH17 cells in development: an updated view of their molecular identity and genetic programming. Nat Rev Immunol. 2008 May;8(5):337-48.

94 Noonan K, Marchionni L, Anderson J, Pardoll D, Roodman GD, Borrello I. A novel role of IL-17-producing lymphocytes in mediating lytic bone disease in multiple myeloma. Blood. 2010 Nov 4;116(18):3554-63.

95 Dhodapkar KM, Barbuto S, Matthews P, Kukreja A, Mazumder A, Vesole D, et al. Dendritic cells mediate the induction of polyfunctional human IL17-producing cells (Th17-1 cells) enriched in the bone marrow of patients with myeloma. Blood. $2008 \mathrm{Oct}$ 1;112(7):2878-85.

96 Prabhala RH, Pelluru D, Fulciniti M, Prabhala HK, Nanjappa P, Song W, et al. Elevated IL-17 produced by TH17 cells promotes myeloma cell growth and inhibits immune function in multiple myeloma. Blood. 2010 Jul 1;115(26):5385-92.

97 Baxter AG, Hodgkin PD. Activation rules: the two-signal theories of immune activation. Nat Rev Immunol. 2002 Jun;2(6):43946.

98 Song W, van der Vliet HJ, Tai YT, Prabhala R, Wang R, Podar K, et al. Generation of antitumor invariant natural killer $\mathrm{T}$ cell lines in multiple myeloma and promotion of their functions via lenalidomide: a strategy for immunotherapy. Clin Cancer Res. 2008 Noy 1;14(21):6955-62.

99 Mateos MV, Blacklock H, Schjesvold F, Oriol A, Simpson D, George A, et al. Pembrolizumab plus pomalidomide and dexamethasone for patients with relapsed or refractory multiple myeloma (KEYNOTE-183): a randomised, open-label, phase 3 trial. Lancet Haematol. 2019 Sep;6(9):e459-69.

100 Ribrag V, Avigan DE, Green DJ, Wise-Draper T, Posada JG, Vij R, et al. Phase $1 \mathrm{~b}$ trial of pembrolizumab monotherapy for relapsed/ refractory multiple myeloma: KEYNOTE-013. Br J Haematol. 2019 Aug; 186(3):e41-4

101 Usmani SZ, Schjesvold F, Oriol A, Karlin L, Cavo M, Rifkin RM, et al. Pembrolizumab plus lenalidomide and dexamethasone for patients with treatment-naive multiple myeloma (KEYNOTE-185): a randomised, open-label, phase 3 trial. Lancet Haematol. 2019 Sep;6(9):e448-58. 